\title{
Aging-related Repositioned Drugs, Donepezil and Sildenafil Citrate, Increase Apoptosis of Anti-mitotic Drug-resistant KBV20C Cells Through Different Molecular Mechanisms
}

\author{
JI YEONG KIM*, JI YEON SON*, BYUNG-MU LEE, HYUNG SIK KIM and SUNGPIL YOON \\ School of Pharmacy, Sungkyunkwan University, Suwon, Republic of Korea
}

\begin{abstract}
Background/Aim: The study focused on identifying the mechanisms or drugs that could sensitize $P$-glycoprotein (P-gp)-overexpressing resistant KBV20C cancer cells to halaven (HAL) or vincristine (VIC) treatment. Materials and Methods: Based on the relatively low dose or $I C_{50}$ values for sensitizing anti-mitotic drug-resistant KBV20C cells, the aging-related drugs donepezil (DON) and sildenafil citrate (SID) were selected. Fluorescence-activated cell sorting (FACS), western blotting, and annexin $V$ analyses were performed to investigate the mechanism of action of DON and SID in HAL-treated KBV20C cells. Results: DON or SID reduced cell viability, increased $G_{2}$ arrest, and up-regulated the expression of the DNA damaging protein $\mathrm{pH} 2 \mathrm{AX}$ when used as co-treatment with HAL. DON and SID induced both early and late apoptosis in KBV20C cells in response to HAL treatment, without increasing autophagy. VIC-DON and VIC-SID co-treatments increased sensitization of KBV2OC cells, suggesting that DON and SID can be combined with other anti-mitotic drugs for sensitizing resistant cancer cells. When the sensitization efficacies of DON and SID were compared to that of the anti-psychotic repositioned drug fluphenazine (FLU), $H A L$ SID or HAL-FLU co-treatments were found to have better sensitization effects than $H A L-D O N$ suggesting that $H A L-$ SID sensitization mechanism is different from that of $H A L$ DON. In addition, DON was found to have higher P-gp inhibitory activity than FLU or SID. Conclusion: These results suggest that $H A L-F L U$ or $H A L-S I D$ sensitization in
\end{abstract}

*These Authors contributed equally to this work.

Correspondence to: Sungpil Yoon, Ph.D., School of Pharmacy, Sungkyunkwan University, 2066 Seobu-ro, Jangan-gu, Suwon, Gyeonggi-do, 16419, Republic of Korea. Tel: +82 1055024893, Fax: +82 312928800, e-mail: syoon88@gmail.com.

Key Words: Donepezil, sildenafil citrate, repositioning drug, cancer, $\mathrm{P}$-gp, drug resistance, apoptosis.
KBV20C cells involves both cytotoxic and P-gp inhibitory effects, whereas HAL-DON sensitization may involve only $P$ gp inhibitory activity of DON.

Anti-mitotic drugs inhibit mitosis by targeting microtubules and preventing their polymerization or depolymerization. Paclitaxel, docetaxel, vincristine, vinorelbine, vinblastine, and halaven are examples of anti-mitotic drugs (1-4). Although anti-mitotic drugs are widely used to treat cancer, cancer cells can develop resistance to these drugs in various ways. One such mechanism is overexpression of P-glycoprotein (P-gp) on cell membranes. P-gp is a membrane channel that can pump out anti-mitotic drugs and thus limiting drug-induced toxicity (5-8). Identifying sensitization mechanisms or drugs for cancer cells that overexpress P-gp would lead to better treatment of patients who develop resistance to anti-mitotic drugs.

Drug repositioning or drug repurposing is the application of known drugs for new indications $(9,10)$. It has been used for the treatment of various diseases and has advantages such as low cost and avoidance of a significant number of toxicity tests, which is a time-consuming process (9-11). It is a powerful tool to identify effective treatment options for new diseases in a timely manner. For example, the urgent need for pharmacological treatments for resistant cancer can be efficiently addressed with drug repositioning, and these drugs can be applied to human patients at a relatively faster pace. Successful application of the anti-angiogenic drug thalidomide for cancer treatment is an example of drug repositioning (9-11).

This study, aimed at identifying novel mechanisms of repositioned drugs: sensitization of resistant cells, inhibition of P-gp expression, or improvement of efficacy of repositioned drugs when used in combination with chemotherapeutic drugs. It was found that low doses of donepezil (DON) and sildenafil citrate (SID), which are aging-related drugs used for Alzheimer's or erectile dysfunction, can sensitize anti-mitotic drug-resistant KBV20C cells. Furthermore, the sensitization mechanism 
involve apoptosis, $\mathrm{G}_{2}$ arrest, and P-gp inhibition. Notably, SID or the anti-psychotic drug FLU were found to be more effective than DON in sensitizing HAL-treated KBV20C cells. These findings will contribute to the development of P-gp inhibitor-based therapies for the co-treatment of highly drug-resistant tumors.

\section{Materials and Methods}

Reagents and cell culture. Rhodamine123 (Rhodamine), FLU, and verapamil (VER) were purchased from Sigma-Aldrich (St. Louis, MO, USA). VIC was purchased from Enzo Life Sciences (Farmingdale, NY, USA). Donepezil and sildenafil citrate were purchased from Selleckchem (Houston, TX, USA). Aqueous solutions of HAL (Eisai Korea, Seoul, South Korea) were obtained from the National Cancer Center in South Korea.

Antibodies against p21 and cleaved poly ADP ribose polymerase (C-PARP) were obtained from Cell Signaling Technology (Danvers, MA, USA). Antibodies against $\beta$-actin, CDK4, pRB, cyclin D1, cyclin B1, cyclin E, LC3B, Beclin1, Atg5, pErk, pAkt, and pJnk were obtained from Santa Cruz Biotechnology (Santa Cruz, CA, USA). The antibody against $\mathrm{pH} 2 \mathrm{AX}$ was obtained from Abcam (Cambridge, UK).

Human oral squamous carcinoma cell line, KB, and its multidrug-resistant subline, KBV20C, were obtained from Dr. Yong Kee Kim (College of Pharmacy, Sookmyung Women's University, Seoul, Republic of Korea) and have been previously described (1215). All cell lines were cultured in RPMI 1640 containing $10 \%$ fetal bovine serum, $100 \mathrm{U} / \mathrm{ml}$ penicillin, and $100 \mu \mathrm{g} / \mathrm{ml}$ streptomycin (WelGENE, Daegu, South Korea).

Microscopic observation. Cells grown in 60-mm diameter dishes were treated with the indicated drugs for the indicated times. The medium was removed, and phosphate-buffered saline (PBS) was added into each dish. Cells were examined immediately in two independent experiments using an ECLIPSE Ts2 inverted routine microscope (Nikon, Tokyo, Japan) with a $4 \times$ or a $10 \times$ objective lens (Nikon's Microscopy U).

Rhodamine uptake tests. The tests used to assess the ability of a drug to inhibit P-gp were based on a previously described method (12-15). Briefly, cells grown in 60-mm diameter dishes were treated and incubated with the indicated drugs for $24 \mathrm{~h}$ at $37^{\circ} \mathrm{C}$. Cells were then incubated with $2 \mu \mathrm{g} / \mathrm{ml}$ rhodamine for $1 \mathrm{~h} 30 \mathrm{~min}$ at $37^{\circ} \mathrm{C}$. The medium was removed, and the cells were washed with PBS. The stained cells were analyzed in two independent experiments using a Guava EasyCyte Plus Flow Cytometer (Merck Millipore, Billerica, MA, USA).

Fluorescence-activated cell sorting (FACS) analysis. FACS analysis was performed as previously described (14-17). Cells were grown in 60 -mm diameter dishes and treated with the indicated drugs for the prescribed times. The cells were then dislodged by trypsin and pelleted by centrifugation. The pelleted cells were washed thoroughly with PBS, suspended in $75 \%$ ethanol for at least $1 \mathrm{~h}$ at $4^{\circ} \mathrm{C}$, washed with PBS, and re-suspended in a cold propidium iodide (PI) staining solution $(100 \mu \mathrm{g} / \mathrm{ml} \mathrm{RNase} \mathrm{A}$ and $50 \mu \mathrm{g} / \mathrm{ml} \mathrm{PI}$ in PBS) for $30 \mathrm{~min}$ at $37^{\circ} \mathrm{C}$. The stained cells were analyzed in two independent experiments for relative DNA content using a Guava EasyCyte Plus Flow Cytometer (Merck Millipore, Billerica, MA, USA).
Annexin $V$ analysis. Annexin $\mathrm{V}$ analysis was conducted by using the annexin V-fluorescein isothiocyanate (FITC) staining kit (BD Bioscience, Franklin, NJ, USA) as previously described (14-17). Cells were grown in 60-mm diameter dishes and treated with the indicated drugs. The cells were then dislodged by trypsin and pelleted by centrifugation. The pelleted cells were washed with PBS. Cells in $100 \mu \mathrm{l}$ of binding buffer received $5 \mu \mathrm{l}$ of Annexin VFITC and $5 \mu \mathrm{l}$ of PI and were, then, incubated for $15 \mathrm{~min}$ at room temperature. The stained cells were analyzed in two independent experiments using a Guava EasyCyte Plus Flow Cytometer (Merck Millipore, Burlington, MA, USA).

Western blot analysis. Total cellular proteins were extracted as previously described $(12,13,15,16)$. Briefly, cells grown in 60-mm dishes were washed twice with cold PBS and detached with scrapers. For total protein isolation, cells were suspended in PROPREP $^{\text {TM }}$ protein extraction solution (iNtRON, Seongnam, South Korea) and placed on ice for $30 \mathrm{~min}$. The suspension was collected after centrifugation at $15,000 \times g$ for $5 \mathrm{~min}$ at $4^{\circ} \mathrm{C}$. Protein concentrations were measured by using a protein assay kit (Bio-Rad, Hercules, CA, USA) according to the manufacturer's instructions. The proteins were resolved by sodium dodecyl sulfatepolyacrylamide gel electrophoresis (SDS-PAGE) and subjected to western blot analysis as previously described $(12,13,15,16)$.

Cell viability assay. Cell proliferation was measured by a colorimetric assay using the EZ-CyTox cell viability assay kit (Daeillab, South Korea) according to the manufacturer's instructions. Briefly, cells grown in wells of 96-well plates were incubated with $10 \mu \mathrm{l}$ of EZ-CyTox solution for $1-2 \mathrm{~h}$ at $37^{\circ} \mathrm{C}$. Absorbance at $450 \mathrm{~nm}$ was determined immediately using the VERSA MAX Microplate Reader (Molecular Devices Corp., Sunnyvale, CA, USA). All experiments were performed at least in triplicate and repeated twice.

Statistical analysis. Data are presented as mean \pm standard deviation (S.D.). Statistical analysis was performed by using Student's $t$-test and one-way analysis of variance (ANOVA) followed by a multiplecomparison test. Results were considered statistically significant compared to those of the control $(*)$ when $p<0.05$.

\section{Results}

Co-treatment with repositioning drugs (DON or SID) increases apoptosis of HAL -resistant KBV20C cancer cells. We aimed to identify repositioning drugs, which sensitize resistant cells, or improve the efficacy of chemotherapeutic drugs when used in combination (9-11). In particular, we focused on the sensitization of cancer cells resistant to the anti-mitotic drug, HAL, which has been recently developed and used in the treatment of metastatic cancers (18-20). Previously, we have found that the KBV20C cell line is a very useful model of highly HAL-resistant cancer cells (21, 22). The concentration of HAL required for a similar response in the KBV20C cells was approximately 500-fold higher than that required for the parental drug-sensitive $\mathrm{KB}$ cells $(21,22)$. Low doses of two aging-related drugs, DON and SID increased sensitization of HAL-treated KBV20C 
A
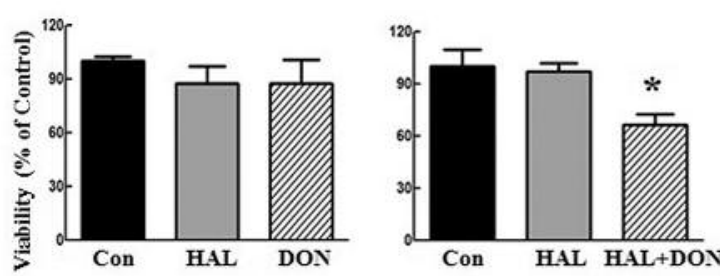

B

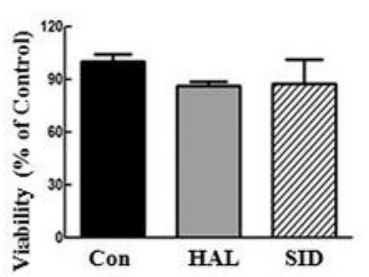

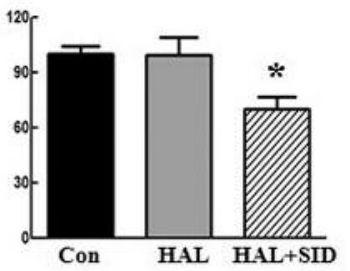

C

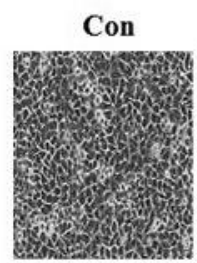

HAL

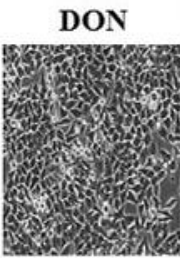

HAL+DON
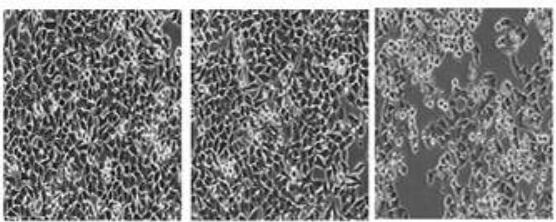

E

Con

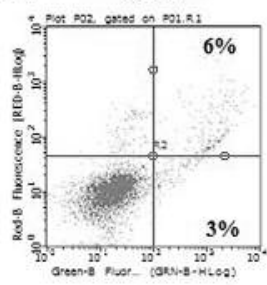

HAL
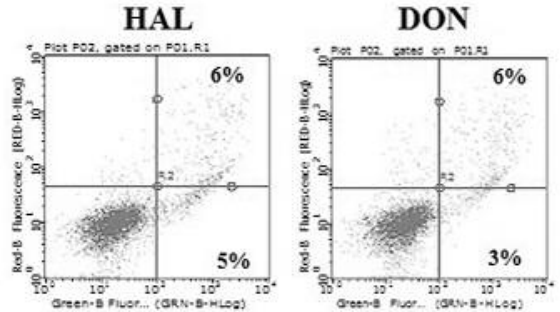

D

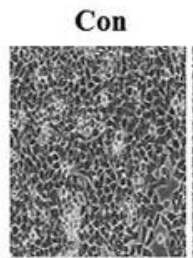

HAL

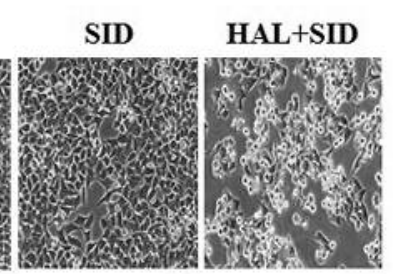

SID

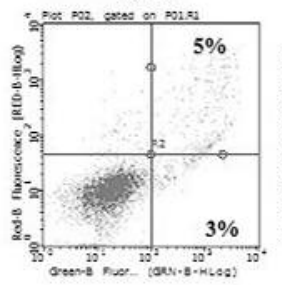

HAL+DON

HAL+SID
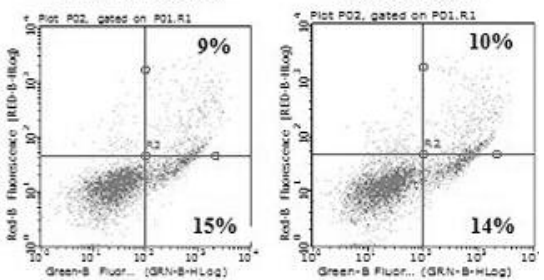

F

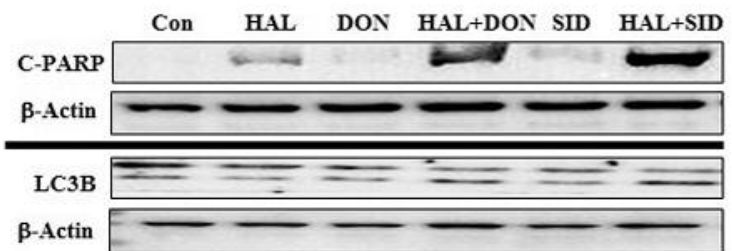

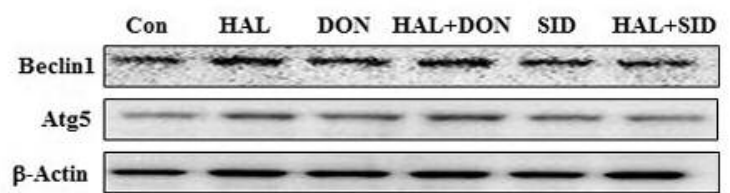

Figure 1. Co-treatment of KBV20C cancer cells with repositioned drugs DON or SID and HAL increased apoptosis . (A-B) KBV20C cells were plated on 96-well plates and grown to 30-40\% confluence. The cells were then stimulated for $48 \mathrm{~h}$ with $50 \mathrm{ng} / \mathrm{ml} \mathrm{HAL}$ (HAL), $5 \mu \mathrm{M}$ donepezil (DON), $5 \mu M$ sildenafil citrate (SID), $50 \mathrm{ng} / \mathrm{ml} H A L$ plus $5 \mu M$ donepezil (HAL+DON), $50 \mathrm{ng} / \mathrm{ml} \mathrm{HAL} \mathrm{plus} 5 \mu M$ sildenafil citrate (HAL+SID), or $0.1 \%$ DMSO (Con). Cell viability assay was performed as described in "Materials and methods". The data are presented as the mean \pm S.D. of at least two experiments repeated in triplicate experiments. Statistical analysis was conducted using one-way analysis of variance (ANOVA) followed by multiple-comparison test; $* p<0.05$ compared to the corresponding control. (C-D) KBV20C cells were grown on 60 mm-diameter dishes and treated with $50 \mathrm{ng} / \mathrm{ml} \mathrm{HAL}(\mathrm{HAL}$ ), $5 \mu \mathrm{M}$ donepezil (DON), $5 \mu \mathrm{M}$ sildenafil citrate (SID), $50 \mathrm{ng} / \mathrm{ml}$ HAL plus $5 \mu \mathrm{M}$ donepezil (HAL+DON), $50 \mathrm{ng} / \mathrm{ml}$ HAL plus $5 \mu \mathrm{M}$ sildenafil citrate (HAL+SID), or 0.1\% DMSO (Con). After 1 day, all cells were observed using an inverted microscope at $\times 10$ magnification (scale bar $=100 \mu \mathrm{m}$ ). (E) KBV20C cells were grown on $60 \mathrm{~mm}$-diameter dishes and stimulated with $50 \mathrm{ng} / \mathrm{ml} \mathrm{HAL}$ (HAL), $5 \mu \mathrm{M}$ donepezil (DON), $5 \mu \mathrm{M}$ sildenafil citrate (SID), $50 \mathrm{ng} / \mathrm{ml} H A L$ plus $5 \mu \mathrm{M}$ donepezil (HAL+DON), $50 \mathrm{ng} / \mathrm{ml}$ HAL plus $5 \mu \mathrm{M}$ sildenafil citrate $(H A L+S I D)$, or $0.1 \%$ DMSO (Con). After 24 h, Annexin V analyses were performed as described in Materials and Methods. $(F)$ KBV20C cells were plated on $60 \mathrm{~mm}$-diameter dishes and treated with $50 \mathrm{ng} / \mathrm{ml} \mathrm{HAL} \mathrm{(HAL),} 10 \mu \mathrm{M}$ donepezil (DON), $10 \mu \mathrm{M}$ sildenafil citrate (SID), $50 \mathrm{ng} / \mathrm{ml} \mathrm{HAL}$ plus $10 \mu \mathrm{M}$ donepezil (HAL+DON), $50 \mathrm{ng} / \mathrm{ml} H A L$ plus $10 \mu \mathrm{M}$ sildenafil citrate (HAL+SID), or 0.1\% DMSO (Con). After $24 \mathrm{~h}$, western blot analysis was performed using antibodies against C-PARP, LC 3B, Beclin1, Atg5, and $\beta$-actin.

cancer cells. As shown in Figure 1A and B, co-treatment with DON or SID reduced the proliferation of HAL-treated KBV20C cells compared to a single treatment using either $5 \mu \mathrm{M}$ of DON or SID. Microscopic observation confirmed sensitization of HAL-DON or HAL-SID co-treated cells (Figure $1 \mathrm{C}$ and D). Furthermore, annexin $\mathrm{V}$ staining was analyzed as a marker of apoptosis $(23,24)$. As shown in
Figure 1E, co-treatment with HAL and DON or SID increased the number of cells in both early and late phases of apoptosis compared to those reported for the treatment with DON or SID alone, suggesting that DON and SID sensitize KBV20C cells to HAL. To confirm increased apoptosis in co-treated cells C-PARP production was measured $(17,23,24)$. As can be seen in Figure 1F, C-PARP 
A

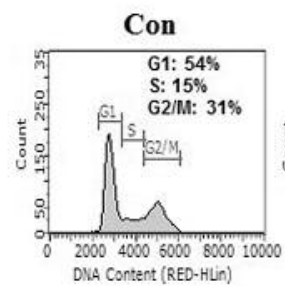

B

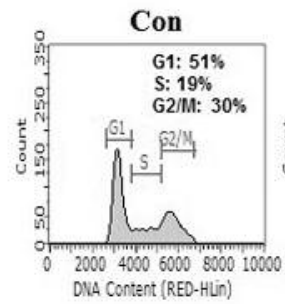

HAL

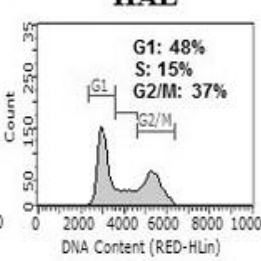

HAL

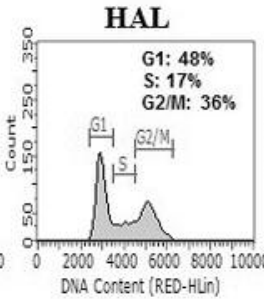

DON-5

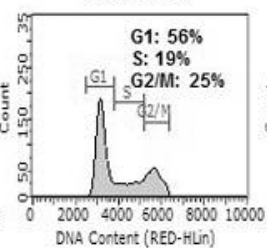

SID-5

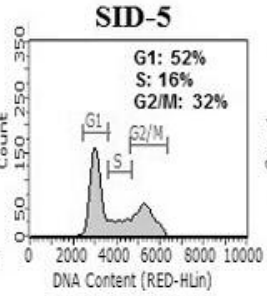

DON-10

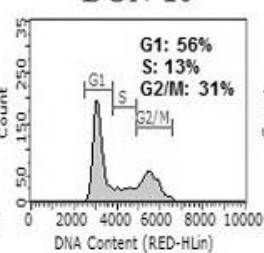

SID-10

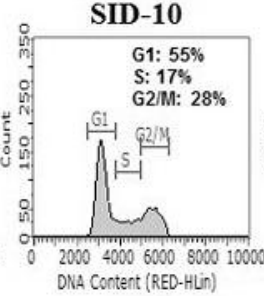

HAL+DON-5
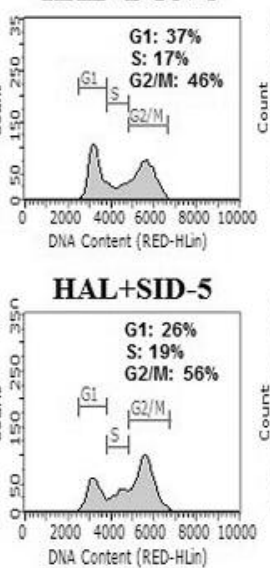

HAL+DON-10

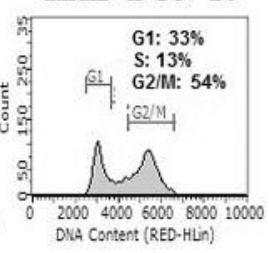

HAL+SID-10

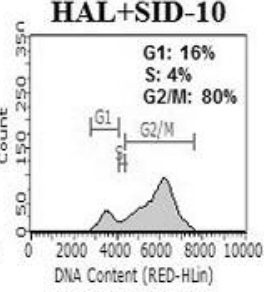

C

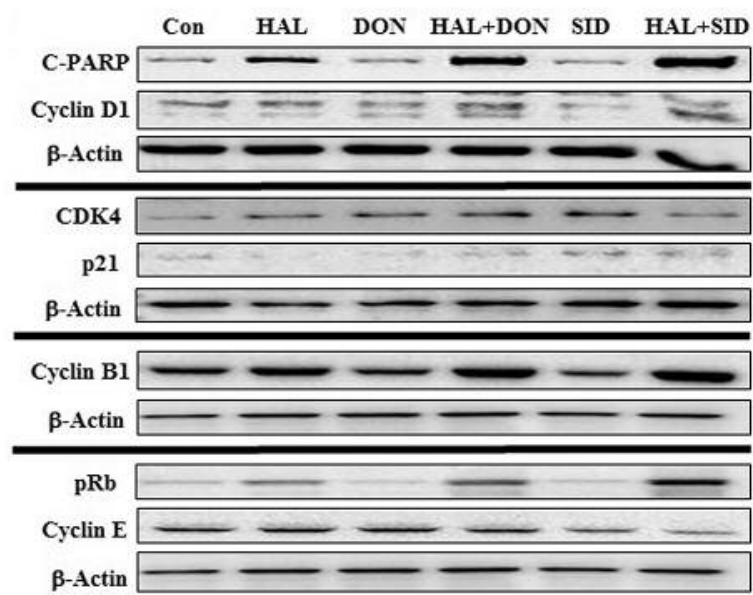

D
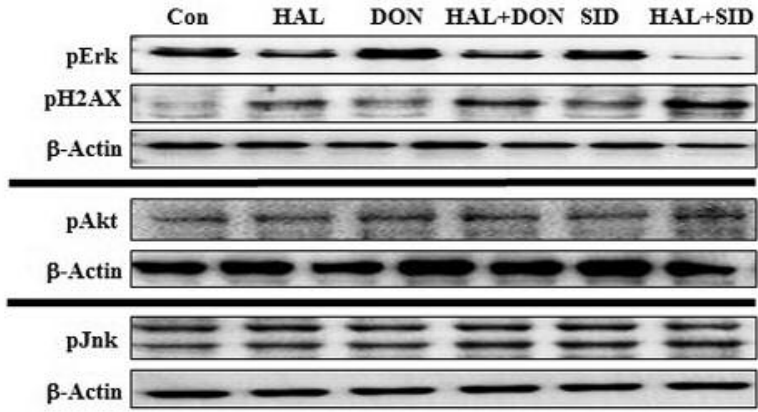

Figure 2. Co-treatment with SID sensitized KBV20C cells to HAL treatment to a greater extent than DON. KBV20C cells were grown on 60 mmdiameter dishes and treated with $50 \mathrm{ng} / \mathrm{ml} H A L(H A L), 5 \mu M$ donepezil (DON-5), $10 \mu M$ donepezil (DON-10), $5 \mu M$ sildenafil citrate (SID-5), $10 \mu \mathrm{M}$ sildenafil citrate (SID-10), $50 \mathrm{ng} / \mathrm{ml}$ HAL plus $5 \mu \mathrm{M}$ donepezil (HAL+DON-5), $50 \mathrm{ng} / \mathrm{ml}$ HAL plus 10 $\mu M$ donepezil (HAL+DON-10), $50 \mathrm{ng} / \mathrm{ml} \mathrm{HAL}$ plus $5 \mu \mathrm{M}$ sildenafil citrate (HAL+SID-5), $50 \mathrm{ng} / \mathrm{ml} \mathrm{HAL}$ plus $10 \mu \mathrm{M}$ sildenafil citrate (HAL+SID-10), or 0.1\% DMSO (Con). A-B) After $24 \mathrm{~h}$, FACS analyses were performed as described in Materials and Methods. (C-D) After $24 \mathrm{~h}$, western blot analysis was performed using antibodies against C-PARP, cylin D1, CDK4, p21, cyclin B1, pRb, cyclin E, pErk, pH2AX, pAkt, pJnk, and $\beta$-actin.

expression increased in HAL-DON or HAL-SID co-treated cells. These results indicate that co-treatment with HALDON or HAL-SID increased apoptosis of drug-resistant KBV20C cells. Moreover, we tested whether autophagic death is increased in co-treatments. However, as it can be seen in Figure $1 \mathrm{~F}$, there were no significant changes in the expression of autophagic markers (LC3B, Beclin1, and Atg5) upon HAL-DON or HAL-SID co-treatments. These results indicate that the mechanism of sensitization in the cotreatments does not involve autophagic pathways.

Co-treatment with SID sensitizes KBV20C cells to a greater extent than DON. Next, to assess the sensitization efficiency of the two repositioning drugs, DON and SID, to the treatment of KBV20C cells with FACS analyses of the treated cells was performed. As shown in Figure 2A and B, HAL-DON or HALSID co-treatments increased the number of cells arrested in the $\mathrm{G}_{2}$ phase compared to that observed with single treatments with either agent. These results suggest that HAL-DON or HAL-SID co-treatments increased apoptosis of drug-resistant KBV20C cells via $\mathrm{G}_{2}$ cell-cycle arrest. A positive relationship was also detected between the increased dose of DON or SID and the proportion of HAL-treated cells in $\mathrm{G}_{2}$ arrest (Figure 2A and $\mathrm{B}$ ), suggesting that increased doses of drugs increases sensitization to HAL treatment. Two-fold lower doses of SID, co-applied with HAL, were required to have the same effect 
A

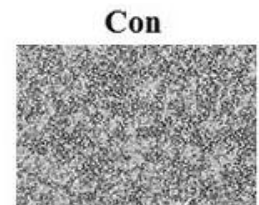

VER-10

DON-5
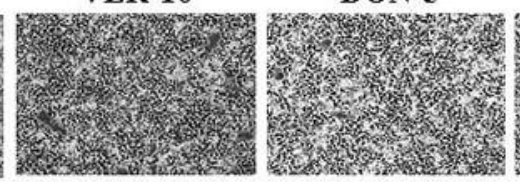

DON-10
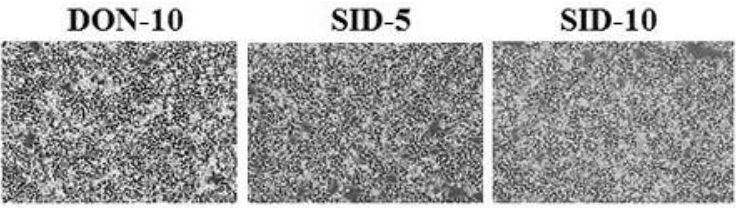

HAL

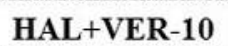

HAL+DON-5

HAL +DON-10

HAL+SID-5

HAL+SID-10
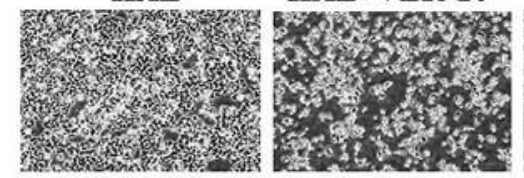

B
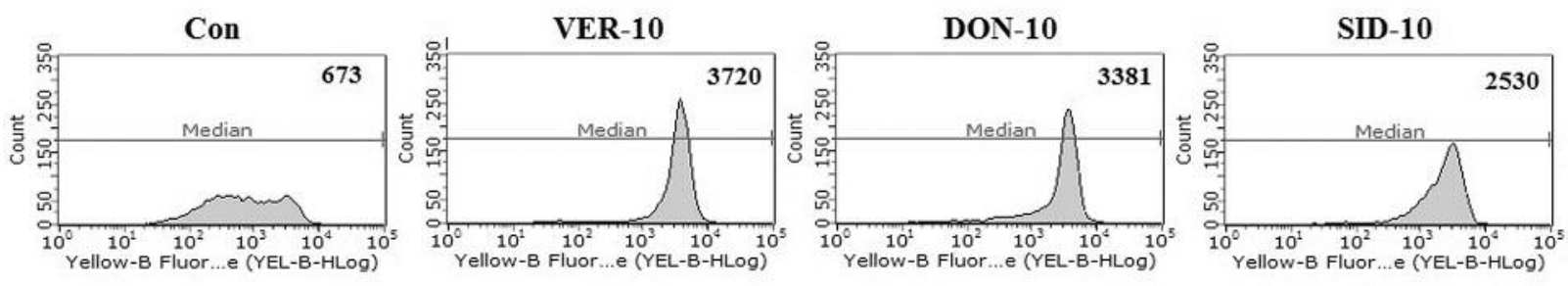

C
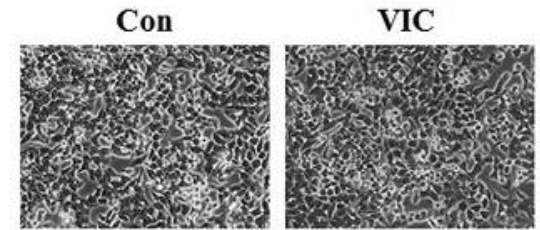

VER-10

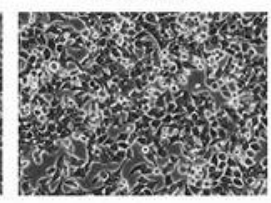

DON-10

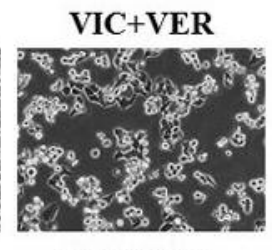

$\mathrm{VIC}+\mathrm{DON}$

D
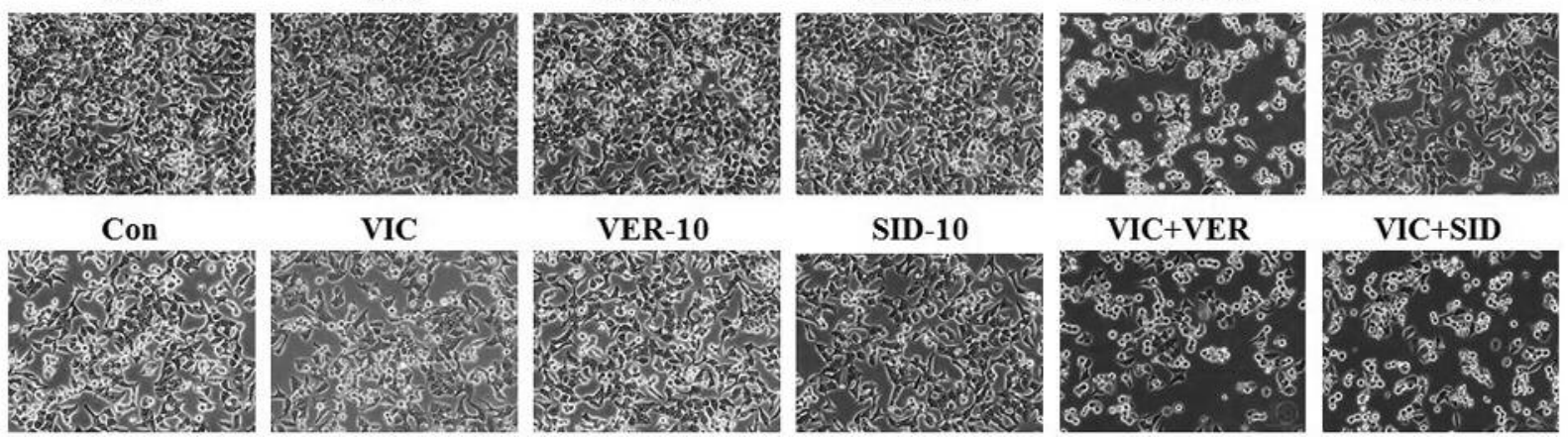

$\mathrm{VIC}+\mathrm{SID}$

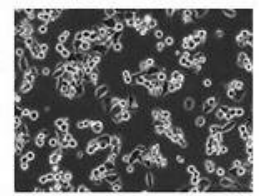

Figure 3. SID and verapamil showed similar sensitization of KBV20C cells, but through a different mechanism, to HAL treatment. (A) KBV20C cells were grown on $60 \mathrm{~mm}$-diameter dishes and treated with $50 \mathrm{ng} / \mathrm{ml} H A L$ (HAL), $10 \mu \mathrm{M}$ verapamil (VER-10), $5 \mu \mathrm{M}$ donepezil (DON-5), $10 \mu \mathrm{M}$ donepezil (DON-10), $5 \mu \mathrm{M}$ sildenafil citrate (SID-5), $10 \mu \mathrm{M}$ sildenafil citrate (SID-10), $50 \mathrm{ng} / \mathrm{ml}$ HAL plus $10 \mu \mathrm{M}$ verapamil (HAL+VER), $50 \mathrm{ng} / \mathrm{ml}$ HAL plus $5 \mu \mathrm{M}$ donepezil (HAL+DON-5), $50 \mathrm{ng} / \mathrm{ml}$ HAL plus $10 \mu \mathrm{M}$ donepezil (HAL+DON-10), $50 \mathrm{ng} / \mathrm{ml}$ HAL plus $5 \mu \mathrm{M}$ sildenafil citrate (HAL+SID-5), $50 \mathrm{ng} / \mathrm{ml}$ HAL plus $10 \mu \mathrm{M}$ sildenafil citrate (HAL+SID-10), or 0.1\% DMSO (Con). After 1 day, all cells were observed using an inverted microscope at $\times 4$ magnification. (B) KBV20C cells were grown on $60 \mathrm{~mm}$-diameter dishes and treated with $10 \mu \mathrm{M}$ verapamil (VER-10), $10 \mu \mathrm{M}$ donepezil (DON-10), $10 \mu \mathrm{M}$ sildenafil citrate (SID-10), or 0.1\% DMSO (Con). After $24 \mathrm{~h}$, all cells were stained with rhodamine123 and examined by FACS analysis, as described in Materials and Methods. (C-D) KBV20C cells were grown on 60 mm-diameter dishes and treated with $5 \mathrm{nM}$ vincristine (VIC), $10 \mu \mathrm{M}$ verapamil (VER-10), $10 \mu \mathrm{M}$ donepezil (DON-10), $10 \mu \mathrm{M}$ sildenafil citrate (SID-10), $5 \mathrm{nM}$ vincristine plus 10 $\mu \mathrm{M}$ verapamil (VIC+VER), $5 \mathrm{nM}$ vincristine plus $10 \mu \mathrm{M}$ donepezil (VIC+DON), $5 \mathrm{nM}$ vincristine plus $10 \mu \mathrm{M}$ sildenafil citrate (VIC+SID), or $0.1 \%$ DMSO (Con). After 1 day, all cells were observed using an inverted microscope at $\times 10$ magnification.

on $\mathrm{G}_{2}$ phase arrest as DON, co-treated with HAL (Figure $2 \mathrm{~A}$ and $\mathrm{B})$. These results suggest that SID has a greater sensitization effect than DON in combination with HAL.

In order to further investigate the expression of proteins involved in $\mathrm{G}_{2}$ arrest $(17,23)$, western blot analysis was performed. As shown in Figure 2C, when the production of C-PARP, an apoptotic marker increased, there were no significant differences in the expression of major cell cyclerelated proteins such us CDK4, cyclin E, and p21. Although a small increase of cyclin D1 levels was found upon co- treatments, the change was negligible and may not have contributed much to the sensitization effect by HAL-DON or HAL-SID co-treatments. Importantly, the expression levels of pRB and cyclin B1 were largely changed following cotreatments, suggesting that those cell cycle proteins may increase $\mathrm{G}_{2}$ arrest in HAL-DON or HAL-SID co-treated KBV20C cells.

Next, the expression of proteins involved in DNA damages and cellular signaling pathways was investigated . As seen in Figure 3D, the levels of $\mathrm{pH} 2 \mathrm{AX}$ protein, a marker 
A
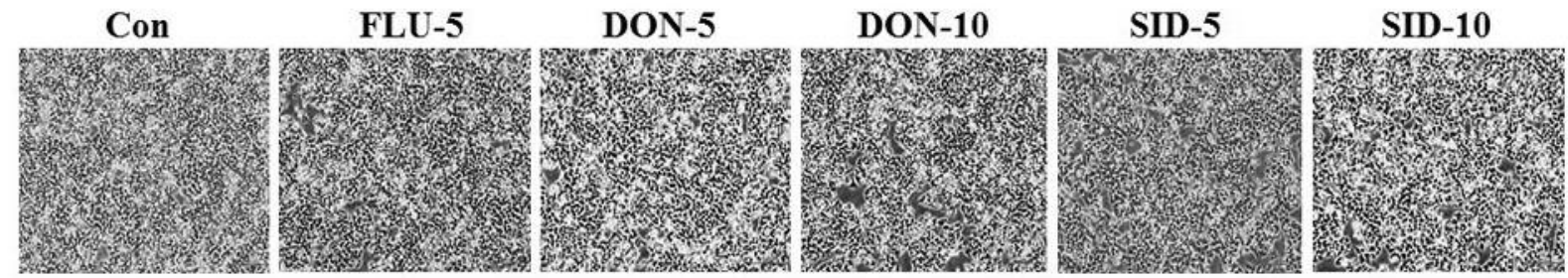

HAL
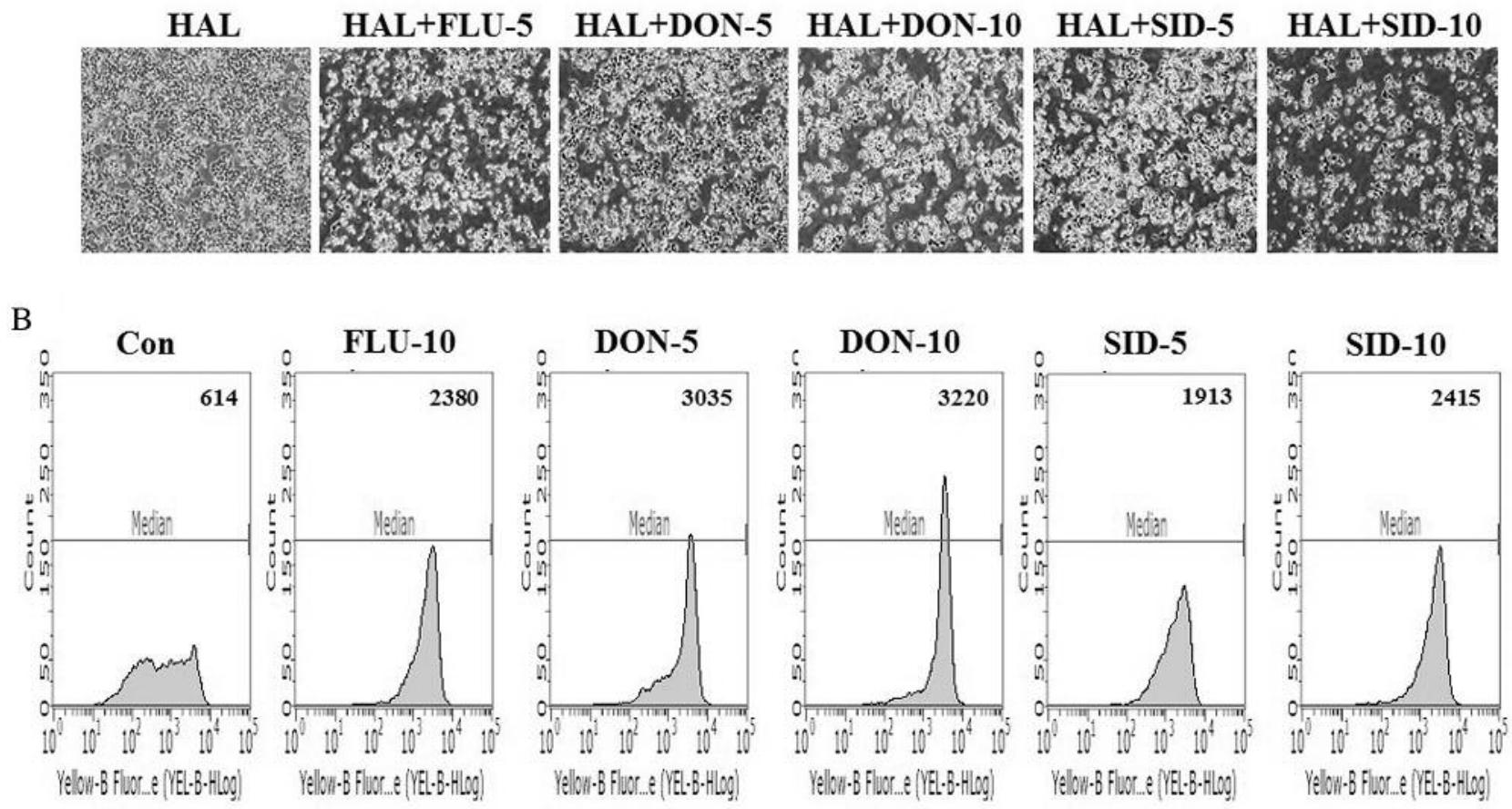

Figure 4. SID and FLU similarly sensitize KBV20C cells to HAL treatment by inhibiting P-gp. (A) KBV20C cells were grown on $60 \mathrm{~mm}$-diameter dishes and treated with $50 \mathrm{ng} / \mathrm{ml} \mathrm{HAL} \mathrm{(HAL),} 5 \mu \mathrm{M}$ fluphenazine (FLU-5), $5 \mu \mathrm{M}$ donepezil (DON-5), $10 \mu M$ donepezil (DON-10), $5 \mu M$ sildenafil citrate (SID-5), $10 \mu \mathrm{M}$ sildenafil citrate (SID-10), $50 \mathrm{ng} / \mathrm{ml}$ HAL plus $5 \mu \mathrm{M}$ fluphenazine (HAL+FLU-5), $50 \mathrm{ng} / \mathrm{ml}$ HAL plus $5 \mu$ M donepezil (HAL+DON-5), $50 \mathrm{ng} / \mathrm{ml} H A L$ plus $10 \mu \mathrm{M}$ donepezil (HAL+DON-10), $50 \mathrm{ng} / \mathrm{ml} \mathrm{HAL}$ plus $5 \mu \mathrm{M}$ sildenafil citrate (HAL+SID-5), $50 \mathrm{ng} / \mathrm{ml} \mathrm{HAL}$ plus $10 \mu \mathrm{M}$ sildenafil citrate (HAL+SID-10), or $0.1 \%$ DMSO (Con). After 1 day, all cells were observed using an inverted microscope at $\times 4$ magnification. (B) KBV20C cells were grown on $60 \mathrm{~mm}$-diameter dishes and treated with $10 \mu \mathrm{M}$ fluphenazine (FLU-10), $5 \mu \mathrm{M}$ donepezil (DON-5), $10 \mu \mathrm{M}$ donepezil (DON-10), $5 \mu \mathrm{M}$ sildenafil citrate (SID-5), $10 \mu \mathrm{M}$ sildenafil citrate (SID-10), or 0.1\% DMSO (Con). After 24 h, all cells were stained with rhodamine 123 and examined by using FACS analysis, as described in Materials and Methods.

of DNA damage, were largely increased following cotreatments. In addition, pErk was down-regulated by HALDON or HAL-SID co-treatment (Figure 3D). These results suggest that DNA damage and pErk pathway may increase apoptosis in HAL-DON or HAL-SID co-treated KBV20C cells. When we compared expression levels between HALDON and HAL-SID treatments, both $\mathrm{pH} 2 \mathrm{AX}$ and pErk levels in HAL-SID co-treatment were found to be more greatly affected than HAL-DON, confirming that SID has a much higher sensitization effect than DON in combination with HAL. It is concluded that DNA-damage and cell-cycle arrest signals ultimately increased apoptosis of HAL-DON or HAL-SID co-treated KBV20C cells via $\mathrm{G}_{2}$ arrest.
Co-treatment with SID has sensitization effects similar to those observed with verapamil in HAL-treated KBV20C cells. The effects of DON or SID were compared with those of the well-known P-gp inhibitor, verapamil $(7,8)$. Cells cotreated with HAL-DON, HAL-SID, or HAL-verapamil were observed under a microscope. As shown in Figure 3A, 10 $\mu \mathrm{M}$ DON or $10 \mu \mathrm{M}$ verapamil similarly sensitized the cells to HAL, reducing KBV20C cellular proliferation. This suggests that the repositioning drug SID can be replaced for the well-known P-gp inhibitor verapamil. However, the same dose of DON was less effective than verapamil, or SID (Figure 3A). Considering that previously developed P-gp inhibitors, including verapamil, are toxic to normal cells (6- 
8 ), it is suggested that DON or SID can be adequate replacements to sensitize $\mathrm{P}$-gp-overexpressing resistant cancer cells in clinics.

SID exhibited lower P-gp inhibitory activity than DON. Next, the P-gp-inhibitory activity of DON and SID were examined in P-gp-overexpressing KBV20C cells, because we assumed that the differences in the degree of P-gp inhibition between DON and SID were responsible for the difference in their sensitizing efficacy in HAL-treated KBV20C cells. However, as shown in Figure 3B, DON showed higher P-gpinhibitory activity than SID. In addition, P-gp inhibition by SID was lower than that by verapamil (Figure 3B). HALSID was found to be more effective than HAL-verapamil or HAL-DON (Figure 3A) suggesting that HAL-SID sensitization of KBV20C cells involves both cytotoxic and P-gp inhibitory effects of SID.

DON or SID increased sensitization of VIC-treated $K B V 20 C$ cells. Next the ability of DON or SID to inhibit pumping-out of other anti-mitotic drugs such as VIC, an anti-mitotic drug routinely used as a chemotherapeutic agent for the treatment of cancer patients, was examined (1-3). DON and SID at low doses had similar sensitizing effects when combined with VIC (Figure 3C and D), as was observed with HAL co-treatment. This finding suggests that DON or SID at low dose can be combined with other anti-mitotic drugs to prevent their effluxfrom the cells.

HAL-SID and HAL-FLU had similar sensitization effects in $H A L$-treated KBV2OC cells with similar P-gp inhibitory activity. The anti-psychotic repositioned drug FLU has been demonstrated to sensitize HAL-treated KBV20C cells (21). Therefore, the efficacy of FLU in sensitizing KBV20C cells to HAL treatment was examined and compared to that of DON or SID. Microscopic observations indicated that HALSID co-treatment had better or similar sensitization effects than HAL-FLU (Figure 4A).

Next, the P-gp-inhibitory activities of FLU and SID were compared in P-gp-overexpressing KBV20C cells. As can be seen in Figure 4B, SID showed similar P-gpinhibitory activity to FLU. HAL-DON presented much lower sensitization effect than HAL-FLU (Figure 4A) although DON has a higher P-gp inhibitory activity than FLU. These results suggest that HAL-FLU or HAL-SID sensitization in KBV20C cells involves both cytotoxic and P-gp inhibitory effects, whereas HAL-DON sensitization may involve only p-gp inhibitory activity of DON. Based on these results (Figures $2 \mathrm{~A}, \mathrm{~B}$ and $4 \mathrm{~A}$ ), it is concluded that SID and FLU have better sensitization effects on HAL-resistant cancer cells than DON and the sensitization mechanisms are similar.

\section{Discussion}

Drug repositioning is the application of known drugs for new indications (9-11). It is a powerful tool for identifying effective treatment options for new diseases in a timely manner. The urgent need for pharmacological treatments for P-gp-overexpressing resistant cancers can be efficiently addressed if novel mechanisms of repositioned drugs are identified, because these drugs can be used without further toxicity evaluation. Repositioned drugs that can sensitize $\mathrm{P}$-gp-overexpressing resistant cancer cells have been reported (12, 13, 17, 21, 22).

The cancer-sensitizing ability of DON and SID, which are aging-related repositioned drugs for Alzheimer's or erectile dysfunction, have been demonstrated in various cancer models (25-29), suggesting that they have potential as chemotherapeutic agents. In this study, DON and SID were found to sensitize P-gp-overexpressing anti-mitotic drug-resistant cancer cells. Our results would contribute to the improvement of efficacy of various chemotherapeutic agents used in combination for the treatment of cancer patients who develop resistance to chemotherapeutic drugs via P-gp-overexpression.

HAL was recently developed and is a promising drug for the treatment of patients in whom anticancer drugs had previously failed (18-20). We previously reported that P-gpoverexpressing KBV20C cells are highly resistant to HAL$(21,22)$. Therefore, KBV20C cells are useful as models of highly HAL-resistant cancer. DON or SID were found to sensitize KBV20C cells to HAL. Detailed analysis was performed to determine the molecular mechanisms underlying the sensitization effects so that repositioned drugs can be applied to human patients at a relatively fast pace, especially in patients resistant to HAL treatment.

Using FACS analysis, it was observed that HAL-SID combination treatment resulted in higher $\mathrm{G}_{2}$ phase arrest than HAL-DON, suggesting that SID may be the better combination partner for HAL in cancer treatment. Since the efflux of HAL by P-gp is the main mechanism for the resistance of KBV20C cells to HAL, the effect of DON or SID on P-gp was examined. We demonstrated that SID has lower P-gp inhibitory activity than DON in preventing pumping-out of HAL. In addition, P-gp inhibition by SID was lower than that by verapamil, the well-known P-gp inhibitor. These findings suggest that SID acts as a weaker P-gp inhibitor than verapamil or DON in resistant KBV20C cells. SID has stronger sensitizing effects than DON in KBV20C cancer cells, suggesting that SID can be more effectively used in combination with HAL at low doses and with reduced toxicity. Thus, SID-mediated sensitization in KBV20C cells involves both SID cytotoxic and P-gp inhibitory effects.

Notably, our results were not limited to HAL co-treatment because it was confirmed that DON or SID similarly sensitize P-gp-overexpressing KBV20C cells to VIC. DON 
or SID can provide sensitization to other anti-mitotic drugresistant cancer cells by inhibiting the pumping-out of drugs. We hypothesize that DON or SID can be used in combination with other cancer drugs for sensitizing resistant cancer cells. However, in vivo studies using animal models are required to assess the efficacy of anti-mitotic drug-DON or -SID combined therapy before investigating its possible use in clinical trials.

We demonstrated that HAL-DON or HAL-SID cotreatment reduced cellular proliferation and increased $\mathrm{G}_{2}$ phase arrest in highly HAL-resistant KBV20C cells. Furthermore, it was found that the levels of the marker of DNA-damage $\mathrm{pH} 2 \mathrm{AX}$, cell-cycle protein $\mathrm{pRb}$, and the proapoptotic protein C-PARP increased after HAL-DON or HAL-SID co-treatment. This is indicative of a mechanism involving $\mathrm{G}_{2}$ phase arrest via DNA damage and an increase in apoptosis. In addition, DON or SID in combination with HAL reduced the expression levels of phosphorylated-Erk (pErk), indicating that Erk pathway regulation may play an important role in the effects of HAL-DON or HAL-SID cotreatment.

FLU has been previously shown to sensitize anti-mitotic drug-resistant KBV20C cells (21). Therefore, we determined whether DON or SID could sensitize HAL-treated resistant KBV20C cells more than FLU. Both P-gp inhibitory activity and sensitization effects of DON, SID, and FLU were analyzed and was found that HAL-SID and HAL-FLU have similar sensitization mechanisms. Since SID or FLU has lower P-gp inhibitory activity than DON, we assume that will be less toxic to normal cells.

Taken together, our results show that drug-resistant KBV20C cells that overexpress P-gp can be sensitized to anti-mitotic drug (HAL or VIC) treatment with repositioned drugs DON, SID, or FLU. Because these repositioned drugs are already in use in clinical settings, the urgent need for pharmacological treatments of drug-resistant cancers can be efficiently addressed, and these drugs may be used to treat drug-resistant patients at a relatively faster pace.

\section{Conflicts of Interest}

The Authors declare no conflicts of interest regarding this study.

\section{Acknowledgements}

The Authors thank Yujin Park for the technical support and preparation of the manuscript. This research was supported by National Research Foundation of Korea (NRF) funded by the Ministry of Education (NRF-2017R1D1A1B03029158).

\section{References}

1 Jordan MA and Wilson L: Microtubules as a target for anticancer drugs. Nat Rev Cancer 4: 253-265, 2004.
2 Kim JH, Yoo HI, Kang HS, Ro J and Yoon S: Salinomycin sensitizes antimitotic drugs-treated cancer cells by increasing apoptosis via the prevention of $\mathrm{G}_{2}$ arrest. Biochem Biophys Res Commun 418: 98-103, 2012.

3 McGrogan BT, Gilmartin B, Carney DN and McCann A: Taxanes, microtubules and chemoresistant breast cancer. Biochim Biophys Acta 1785: 96-132, 2008.

4 Szakacs G, Paterson JK, Ludwig JA, Booth-Genthe C and Gottesman MM: Targeting multidrug resistance in cancer. Nat Rev Drug Discov 5: 219-234, 2006.

5 Chen Z, Shi T, Zhang L, Zhu P, Deng M, Huang C, Hu T, Jiang $\mathrm{L}$ and $\mathrm{Li} \mathrm{J}$ : Mammalian drug efflux transporters of the ATP binding cassette $(\mathrm{ABC})$ family in multidrug resistance: A review of the past decade. Cancer Lett 370: 153-164, 2016.

6 Chufan EE, Kapoor K and Ambudkar SV: Drug-protein hydrogen bonds govern the inhibition of the ATP hydrolysis of the multidrug transporter P-glycoprotein. Biochem Pharmacol 101: 40-53, 2016.

7 Shukla S, Wu CP and Ambudkar SV: Development of inhibitors of ATP-binding cassette drug transporters: present status and challenges. Expert Opin Drug Metab Toxicol 4: 205-223, 2008.

8 Yang K, Wu J and Li X: Recent advances in the research of Pglycoprotein inhibitors. Biosci Trends 2: 137-146, 2008.

9 Clark KB: New therapeutic bearings for repositioned drugs. Curr Top Med Chem 13: 2281-2282, 2013.

10 Pantziarka P and Cairns L: Recycling existing drugs for cancer therapy: delivering low cost cancer care. Ecancermedicalscience 8: ed40, 2014.

11 Yoon S: A single treatment of Selenate, a repositioning drug, specifically sensitizes P-gp-overexpressing resistant cancer cells. Cancer Cell Microenviron 2(4), 2015.

12 Cheon JH, Kim JY, Lee BM, Kim HS and Yoon S: P-gp Inhibition by XL019, a JAK2 inhibitor, increases apoptosis of vincristine-treated resistant KBV20C cells with increased p21 and pH2AX expression. Anticancer Res 37: 6761-6769, 2017.

13 Cheon JH, Kim KS, Yadav DK, Kim M, Kim HS and Yoon S: The JAK2 inhibitors CEP-33779 and NVP-BSK805 have high P-gp inhibitory activity and sensitize drug-resistant cancer cells to vincristine. Biochem Biophys Res Commun 490: 1176-1182, 2017.

14 Choi AR, Kim JH, Cheon JH, Kim HS and Yoon S: Attenuation of colchicine toxicity in drug-resistant cancer cells by co-treatment with anti-malarial drugs. Anticancer Res 36: 5859-5866, 2016.

15 Choi AR, Kim JH, Woo YH, Kim HS and Yoon S: Anti-malarial drugs primaquine and chloroquine have different sensitization effects with anti-mitotic drugs in resistant cancer cells. Anticancer Res 36: 1641-1648, 2016.

16 Choi AR, Kim JH, Woo YH, Cheon JH, Kim HS and Yoon S: Co-treatment of LY294002 or MK-2206 with AZD5363 Attenuates AZD5363-induced Increase in the Level of Phosphorylated AKT. Anticancer Res 36: 5849-5858, 2016.

17 Lim JS, Park Y, Lee BM, Kim HS and Yoon S: Co-treatment with celecoxib or NS398 strongly sensitizes resistant cancer cells to antimitotic drugs independent of P-gp inhibition. Anticancer Res 36: 5063-5070, 2016.

18 Dell'Ova M, De Maio E, Guiu S, Roca L, Dalenc F, Durigova A, Pinguet F, Bekhtari K, Jacot W and Pouderoux S: Tumour biology, metastatic sites and taxanes sensitivity as determinants of eribulin mesylate efficacy in breast cancer: results from the ERIBEX retrospective, international, multicenter study. BMC Cancer 15: 659, 2015. 
19 Dybdal-Hargreaves NF, Risinger AL and Mooberry SL: Eribulin mesylate: mechanism of action of a unique microtubule-targeting agent. Clin Cancer Res 21: 2445-2452, 2015.

20 Inoue K, Saito T, Okubo K, Kimizuka K, Yamada H, Sakurai T, Ishizuna K, Hata S, Kai T and Kurosumi M: Phase II clinical study of eribulin monotherapy in Japanese patients with metastatic breast cancer who had well-defined taxane resistance. Breast Cancer Res Treat 157: 295-305, 2016.

21 Cheon JH, Lee BM, Kim HS and Yoon S: Highly Halavenresistant KBV20C cancer cells can be sensitized by co-treatment with fluphenazine. Anticancer Res 36: 5867-5874, 2016.

22 Park Y, Son JY, Lee BM, Kim HS and Yoon S: Highly eribulinresistant KBV20C oral cancer cells can be sensitized by cotreatment with the third-generation P-glycoprotein inhibitor, elacridar, at a low dose. Anticancer Res 37: 4139-4146, 2017.

23 Florian S and Mitchison TJ: Anti-microtubule drugs. Methods Mol Biol 1413: 403-421, 2016.

24 Wang LG, Liu XM, Kreis W and Budman DR: The effect of antimicrotubule agents on signal transduction pathways of apoptosis: a review. Cancer Chemother Pharmacol 44: 355-361, 1999.

25 Correa DD, Kryza-Lacombe M, Baser RE, Beal K and DeAngelis LM: Cognitive effects of donepezil therapy in patients with brain tumors: a pilot study. J Neurooncol 127: 313 319,2016
26 El-Naa MM, Othman M and Younes S: Sildenafil potentiates the antitumor activity of cisplatin by induction of apoptosis and inhibition of proliferation and angiogenesis. Drug Des Devel Ther 10: 3661-3672, 2016.

27 Ki YS, Park EY, Lee HW, Oh MS, Cho YW, Kwon YK, Moon $\mathrm{JH}$ and Lee KT: Donepezil, a potent acetylcholinesterase inhibitor, induces caspase-dependent apoptosis in human promyelocytic leukemia HL-60 cells. Biol Pharm Bull 33: 10541059, 2010.

28 Rapp SR, Case LD, Peiffer A, Naughton MM, Chan MD, Stieber VW, Moore DF Jr, Falchuk SC, Piephoff JV, Edenfield WJ, Giguere JK, Loghin ME and Shaw EG: Donepezil for irradiated brain tumor survivors: a phase III randomized placebo-controlled clinical trial. J Clin Oncol 33: 1653-1659, 2015.

29 Shi Z, Tiwari AK, Patel AS, Fu LW and Chen ZS: Roles of sildenafil in enhancing drug sensitivity in cancer. Cancer Res 71: 3735-3738, 2011.
Received August 7, 2018

Revised August 17, 2018

Accepted August 20, 2018 